\title{
Life cycle of hake and likely management implications
}

\author{
Tore Strømme • Marek R. Lipinski • \\ Paulus Kainge
}

Received: 13 February 2015/Accepted: 1 December 2015/Published online: 12 December 2015

(C) The Author(s) 2015. This article is published with open access at Springerlink.com

\begin{abstract}
Despite its economic and social importance for Namibia and South Africa, limited documented information exists regarding key aspects of the biology of deep-water hake, including its life cycle. This study utilizes data collected through the demersal surveys of the R/V Dr Fridtjof Nansen in South Africa and $F / V$ Blue Sea 1 in Namibia to describe the migratory patterns of deep-water hake in space and time. Furthermore the study investigates aspects of the life cycle of this important species in the Benguela region. Results show that deep-water hake spawns between the western Agulhas Bank and Elands Bay in South Africa with the main nursery ground between Hondeklip Bay and the northern tip of Orange Banks. Deep-water hake in Namibia (up to the Kunene River) and along the south coast of South Africa (eastwards to
\end{abstract}

T. Strømme

Institute of Marine Research, P.O.Box 1870, 5817 Bergen,

Norway

e-mail: tore.stromme@fao.org

M. R. Lipinski ( $\bowtie)$

Department of Ichthyology and Fisheries Science, Rhodes

University, P.O. Box 94, 6140 Grahamstown, South

Africa

e-mail: Lipinski@mweb.co.za;

M.Lipinski@ru.ac.za

P. Kainge

National Marine Information and Research Centre,

Ministry of Fisheries and Marine Resources,

P O Box 912, Swakopmund, Namibia

e-mail: paulus.kainge@mfmr.gov.na
Port Alfred) originate from these grounds, and undertake long-range migrations across latitudes and longitudes, respectively. This hypothesis is supported by the finding that spawning has not been observed in Namibia and there are no small juveniles along the South African south coast from the eastern border of the Agulhas Bank. The proposed pattern implies an interconnection between the Namibian and the South African components of the stock and the consequent need for a revision of the present management regime based on the assumption of stocks confined within the respective national jurisdictions. This study has used length frequency distributions in space and time in order to investigate the life cycle, in terms of origin, movement and population structure in particular, an approach that may also be useful for other widely distributed species.

Keywords Hake $\cdot$ Life cycle $\cdot$ Migrations $\cdot$ Shared stock $\cdot$ Transboundary management

\section{Introduction}

The Cape hake (Merluccius capensis Castelnau, 1861) and the deep water hake (DWH, M. paradoxus Franca, 1960) have been among the most valuable fishery resources in the Benguela region of Africa since the 1950 s, with annual catches that have reached peaks of 800,000 tonnes in the early 1970 s. At present, hake 
sustains fisheries in Namibia and South Africa worth \$570 million (Kobus de Swart 2012; Department of Agriculture, Forestry and Fisheries, South Africa internal report; C.J. Augustyn from the same Department, pers. comm.). Management of these species has been regulated by the International Commission for the South-East Atlantic Fisheries (ICSEAF; Payne and Punt 1995) prior to Namibia's independence in 1990 and the declaration of its Exclusive Economic Zone (EEZ) in the same year. Following independence, Namibia has taken full responsibility for managing the resources within its EEZ and management of the fisheries in both countries is under the assumption of national and discrete stocks for both species. However, while present knowledge indicates that Cape hake includes stocks largely confined within the respective national jurisdictions (Gordoa et al. 1995; Payne and Punt 1995), the situation appears to be less clear for the deep water hake. The traditional view, as reflected in present management practices, is that DWH is not a shared stock. Regular transboundary research surveys could provide an answer to this question, and the Benguela Current Commission (BCC) has directed a lot of its research efforts to clarify this issue. The present study is part of this work.

Sustainable management of shared stocks requires negotiated and cooperative agreements between the countries concerned, as enshrined in the United Nations Convention on the Law of the Sea (UNCLOS). It is therefore essential to clarify the status of DWH off Namibia and South Africa as the basis for developing appropriate management schemes.

Hilborn and Walters (1992, p. 170) strongly advocate that research surveys for assessment purposes should be conducted over the whole geographic range of the stock. However, based on the assumption of discreet DWH stocks in Namibia and South Africa, national surveys have covered only a fraction of the distributional range of the species. A study carried out by the United Nations Development Programme (UNDP) in support of the BCMLE programme (UNDP, undated, internal report) concluded that a major issue in the management of hake in the Benguela region was the lack of transboundary surveys. Considering the results of this study, it was one of the main objectives of the Benguela Environment Fisheries Interaction and Training Programme (BENEFIT) and the Benguela Current Large Marine
Ecosystem (BCLME) programme to bring a regional perspective into DWH research (e.g. Armstrong and Sumaila 2004). Under the auspices of these programmes, synoptic surveys covering most of the distribution range of DWH were carried out in the period 2000-2012 with the RV Dr Fridtjof Nansen and intercalibrated vessels with identical survey design, rigging and sampling procedures.

Here, qualitative characteristics of some life stages are combined with their quantitative distributions of abundance by length classes as a proxy for age. The consistency in distribution patterns is analyzed by comparing annual surveys over a 9-year period. These surveys, and the resulting time series, are designed for a possible future shared stock assessment. Traditionally, hake research in southern African waters (1920-1999) has been intense but selective, leaving several research topics poorly addressed, such as those related to the early life cycle (eggs and larvae and their species identity), spawning location and time, distribution and abundance of various life stages, possible migrations and stock structure, and response to biological and environmental forcing. Research linked to the $\mathrm{R} / \mathrm{V}$ Dr Fridtjof Nansen and the Nansen Programme, ${ }^{1}$ as part of BENEFIT and in cooperation with the BCLME programme has over years addressed several of these topics (von der Heyden et al. 2007a, b, 2010; Stenevik et al. 2008; Field et al. 2008; Grote et al. 2007, 2012a, b). The collected results indicate that the traditional view on $M$. paradoxus general life cycle scheme needs revision. Established views suggest a largely stationary metapopulation with some local inshore-offshore movement, year-round spawning with minor seasonal peaks and weak patterns of geographical hot-spots (Payne and Punt 1995). However, it was suggested (Le Clus et al. 2005a) that this picture may be inadequate, largely due to sampling limitations.

In describing the results, the "life cycle" concept sensu lato is used. The life cycle concept, in contrast to life history (Hutchings 2002), deals simply with common characteristics of subsequent generations passing through life stages, following a geographical and ecological track. In contrast, life history studies deal more with the genetic track of subsequent generations and therefore often use molecular biology

\footnotetext{
${ }^{1}$ Development and cooperation programme in fisheries, funded by Norway.
} 
techniques to explore life history strategies. "Life cycle" concept is applied in the scientific literature as the sequence of descriptions of developmental/growth stages, or a general outline of critical turns in the fish life, from egg via nursery and feeding grounds to spawning. The latter is used in modelling studies, and it is also used here.

The first aim of the present paper is to investigate the migratory patterns of DWH as derived from the geographic distribution of size classes for a 9 year period, monitored at the beginning of each year (January-February). The second aim is to link the new insights with existing knowledge in order to assess to what extent DWH is a shared stock between Namibia and South Africa and if there are any interannual dynamics in the pattern.

\section{Materials and methods}

Survey design and protocols

The surveys used in this study were planned to provide a representative and synoptic sampling of the hake stocks in Namibia and South Africa. Survey design, gears, timing of the surveys and their geographic coverage were adjusted accordingly. However, coverage of the species' full distribution range, from Port Alfred on the South Africa south coast, to Kunene river mouth in northern Namibia proved particularly difficult. Only in 1 year (2010) full coverage was possible (Fig. 1). In all other years (2003 and 2005-2012) coverage was limited to the area between Cape Agulhas and the Kunene river mouth. The surveys involved two research vessels: one trawler $(\mathrm{F} /$ $\mathrm{V}$ Blue Sea 1) in Namibian waters from the Orange River mouth to Kunene, and the R/V Dr Fridtjof Nansen that conducted surveys in South African waters. The surveys in Namibian waters are part of the national annual monitoring of the demersal stocks with January-February identified as the appropriate time of the year for monitoring (Sætersdal et al. 1999), mainly for logistical reasons, i.e. most effective sampling in the prevailing weather conditions. Hence transboundary studies are limited to this season. This choice does not affect results of this study because the array of length frequencies will obey a set of rules spelled out in tested hypotheses (see below) in any period of the year.
Hake research in South Africa conducted by the R/V Dr Fridtjof Nansen from 2000 onwards addressed a wide array of topics. The data analyzed in this study includes those collected during surveys in 2003, and 2005-2012. Year 2004 was not used in the reported analysis because the geographical coverage was incomplete.

In all these surveys, the methodology applied by the two research vessels was standardized and constant over time. A Gisund Super shrimp cum-fish trawl, was used in the surveys by both ships. A description of the trawl and gear is given in Sætersdal et al. 1999. Both vessels used a $20 \mathrm{~m}$ strapping on the warps $50 \mathrm{~m}$ in front of the doors to keep the door and wingspread constant at 50 and $21 \mathrm{~m}$ respectively, independent of trawl depth.

A standard haul was $30 \mathrm{~min}$ at three knots, sometimes reduced to $20 \mathrm{~min}$ in areas of expected high densities. The exact time for start and stop of the trawl operation was determined by SCANMAR sensors. The output from the SCANMAR system was also recorded to facilitate later analysis of bottom contact and door-spread if necessary.

For conversion of catch rates $(\mathrm{kg} / \mathrm{h})$ to fish densities $\left(\mathrm{t} / \mathrm{NM}^{2}\right)$, the effective fishing area was considered as the product of the linear mouth opening $(18.5 \mathrm{~m})$ and the haul length, at a distance over the bottom, based on GPS readings. The area swept for each haul was thus $18.5 \mathrm{~m}$ times the distance trawled, converted to $\mathrm{NM}^{2}$. The catchability coefficient (q), i.e. the fraction of the fish encountered by the trawl that was actually caught, was conservatively assumed equal to 1 , to allow comparison with previous results.

The survey design is based on transect sampling transversal to the coast with $20 \mathrm{NM}$ distance between transects. Stations are semi-randomly allocated along transect with a distance of 10-15 NM and at least at each $100 \mathrm{~m}$ depth interval, with random position inside the interval.

For all valid trawl hauls, either the whole trawl catch was sorted and all species were recorded with their weight and numbers, or a subsample was taken if very small animals were caught or catch was very large. Generally, subsampling was avoided as far as possible. Length measurements (total length) were taken for target species. The length of each fish was recorded to the nearest $1 \mathrm{~cm}$ below. All samples of small hake were checked for species identity by a vertebrae count (usually 3-5 fish were examined in each sample). This method was independently verified 
Fig. 1 Position of the trawl stations during the transboundary surveys off Namibia and South Africa in 2010. Border between Namibia and South Africa is indicated by the straight line

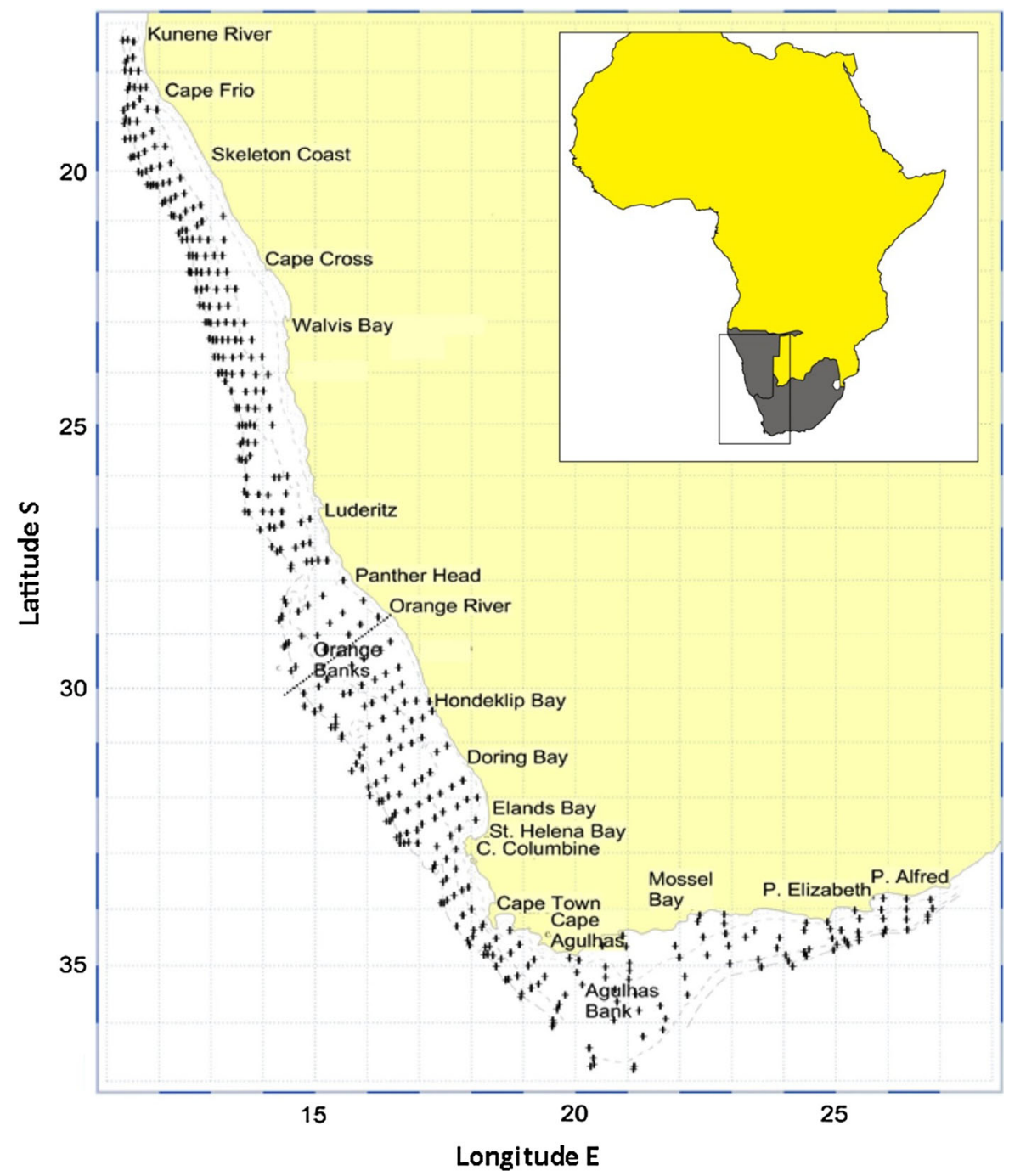

by genetic screening (Matthee and Gopal 2004 unpublished report of the University of Stellenbosch South Africa; Matthee, pers. comm.). An electronic measuring board was used for length measurements, main sample weights were recorded by Scanvaegt electronic balances and a Marel weight was used for single fish and small species measurements.

\section{Compatibility of the South African and Namibian} surveys

The bottom trawl survey time series started in Namibia with the R/V Dr Fridtjof Nansen in 1990 was taken over by commercial trawlers in 2000. An intercalibration study between the R/V Dr Fridtjof Nansen and these trawlers has shown nearly identical results with respect to total catch rates of the hakes (Strømme and Iilende 2001). Recently, Axelsen and Johnsen (2015), have further analysed the length frequency distributions from these intercalibrations and found a slight positive bias in regard to the catchability of larger fish in the commercial vessels. This bias is not expected to affect the results of this study.

\section{Biological sampling}

Both hake species were sampled for sex, maturity stage, gonad weight and stomach content. The maturity scale used (e.g. Botha 1986) was the one adopted by former Sea Fisheries Research Institute, Cape 
Town (immature, active, ripe, ripe and running, spent, inactive). The maturation process and maturity of hake is the subject of a separate study (Jansen et al. 2015), and stomach content data is also not presented here.

Total hake biomass in Namibia and South Africa was calculated by post-stratifying fish densities, i.e. contouring areas with similar density ranges, calculating mean densities and biomass by multiplying these with the corresponding size of the distribution area. The point estimate at each trawl station was combined with length frequency samples taken at the same station to provide biomass (weight) and abundance (number) by length classes $(1 \mathrm{~cm}$ resolution). From the same data, maps of $5 \mathrm{~cm}$ classes were produced for the whole survey area to show the overall distribution by length class. To calculate spatial biomass centroids and percentiles, a second biomass calculation method was applied. Here each sample point was converted to a local biomass sample as a product of the sample point density and the representative area for the station. Representative areas are calculated using triangulation and Thiessen polygons where the weight of each station is halfway to the neighbouring stations. This method also automatically compensates for variation in sampling density. The second biomass method is also used to assess biomass distribution by variables such as latitude and depth and can be applied to the full species sample or to each length class separately. Triangulation allows for easy calculations by computer and is free of subjectivity associated with post stratification and contouring.

Method of addressing aims of the study

The working hypotheses for this study are that (1) if spawning of DWH takes place both along the Namibian and the South African coasts, both adults and juveniles would be found in the respective areas. In this case, sub-stocks spawning locally and with limited active long range migration would have size distributions with all size classes in the distribution area of the stock with a local depth-based size gradient (Payne and Punt 1995). The length composition would mainly reflect natural and fishing mortality. Alternatively, (2) if spawning is located in one or a few well-defined sites with subsequent dispersal and/or long range migration, differentiated size profiles should be found along the distribution range. Consequently, if adults were present, but juveniles missing locally, this would be taken as a sign that the former must have migrated in from an external nursery ground.

Miscellaneous points

The analysis of geographic distribution by length groups may be affected by possible differences in natural and fishing mortalities of these groups along the coast. However, it is considered unlikely that natural or fishing mortality can completely deplete a whole length class locally. When maps show continuity in distributions along the coast and with clear limits, these are assumed to be the distribution limits.

Fish growth and mortality are analyzed by using compounded length distributions at country and stock level. Direct use of length frequencies was preferred to conversion into age-groups, given the technical challenge associated with it in the case of the hake (Wilhelm 2012; de Pontual et al. 2006).

All available data represent snapshots of the January-February distribution of the different size classes and are used to infer their migratory history. While there could be seasonal patterns in the migration of one or more size groups, the approach used should be able to detect changes in distribution and thus reflect the interclass movement of length classes, obviously mainly related to age in the life cycle.

The combination of a systematic sampling design (transects with fixed inter-transect distance) and a semi-random position of the sampling stations is optimal for mapping distributions. Furthermore, it allows a construction of sequence snapshots in space related to distribution and likewise in time-scale related to patterns of dispersion/migration (Gunderson 1993, pp. 15-16).

The present paper has used and quoted a high number of unpublished reports and data, in part to also acknowledge previous work and discussion about the migratory cycle. They are available upon request from the authors.

\section{Results}

Species signature over space and time

Figure 2 shows the distribution limits of 5-cm length classes of DWH overlaid with 5-35 cm length classes (referred to as the expanding phase), while Fig. 3 
shows intermediate lengths $(40-55 \mathrm{~cm})$, referred to as the settling phase, where the fish is distributed throughout its geographical range and overlaid with the contraction phase $(65-75 \mathrm{~cm})$. These figures are based on the results from the survey in 2010, when the full distribution range of the DWH stock was covered. The similarity between the South Africa south coast and Central/Northern Namibia is notable. Absence of small fish (less than $15 \mathrm{~cm}$ ) in both regions is striking. These regions are both characterized by concentrations of hake in the size range $40-55 \mathrm{~cm}$. From these areas, hake probably returns to its spawning grounds. A notable exception is in the east, between Port Elizabeth and Port Alfred in the depth of 300-500 m, where large fish remain in a small enclave, perhaps indicating a small sub-stock that also spawns there.
Figure 4 shows the distribution pattern as derived from the survey in 2005, depicting the centroid for the $5 \mathrm{~cm}$ size classes, from 5 to $65 \mathrm{~cm}$. Following the centroid through the size classes, a pattern emerges which could be interpreted as the "distribution signature" of the stock if consistent through the years, at least for the investigated period (January-February). Figure 5 shows the mean situation for the surveys in 2003 and 2005-2011, and the two extreme situations in 2008 and 2010, the most northern and southern distribution, respectively. By following the movement of the centroid, a consistent picture emerges. The smallest fish tends to move inshore up to the size of $15 \mathrm{~cm}$, then more south and deeper, until $30 \mathrm{~cm}$, from where they start to move north while continuing going deeper. From $55 \mathrm{~cm}$ the fish tends to have a more
Fig. 2 Transboundary distribution of Merluccius paradoxus in JanuaryFebruary 2010 by size classes. The smaller fish are overlaid on the bigger fish, demonstrating expansion from a central area (Saldanha-Hondeklip Bay)

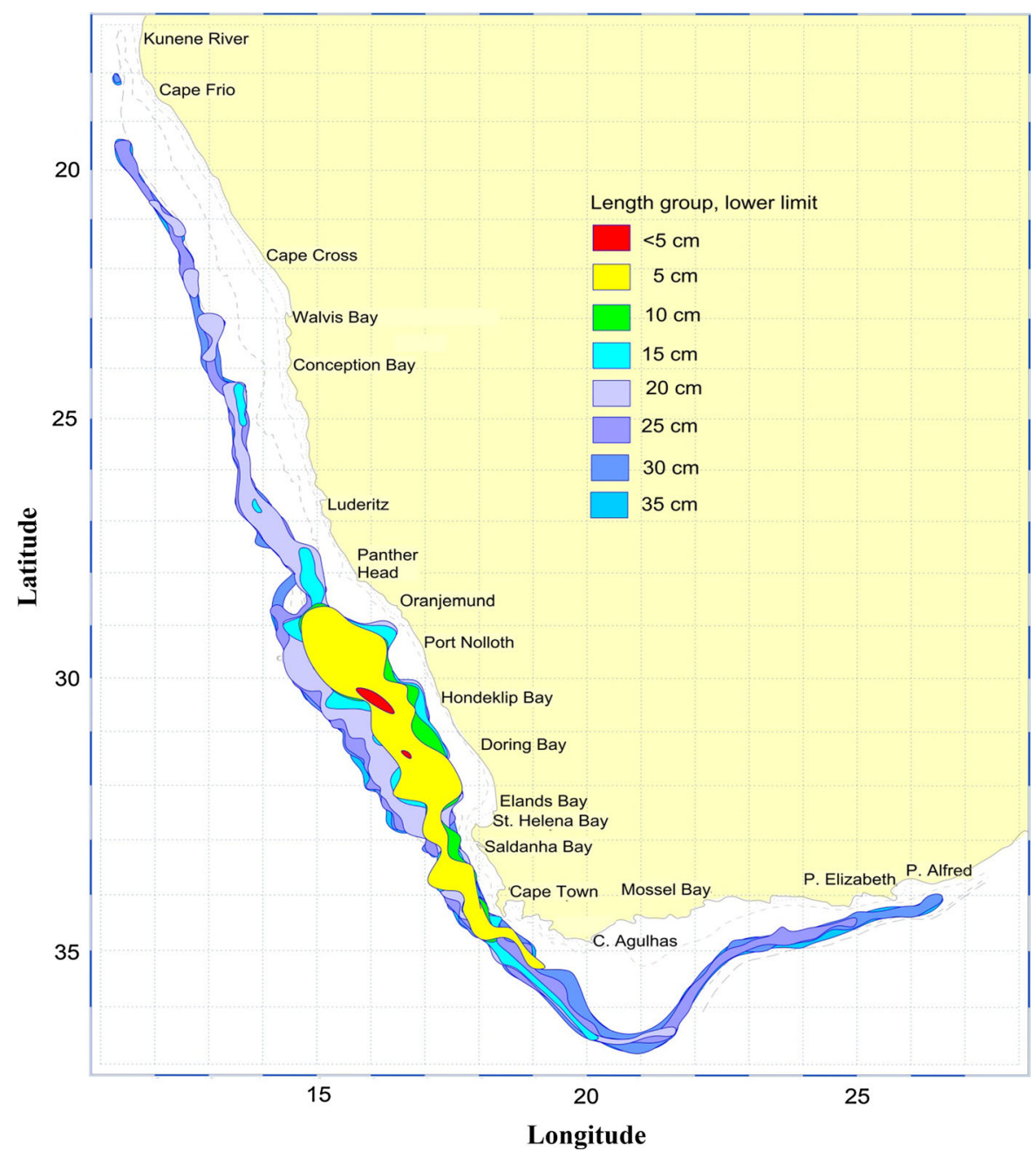


Fig. 3 Transboundary distribution of adult Merluccius paradoxus $(40-55,65$ and $75 \mathrm{~cm})$ in January-February 2010. The bigger fish are overlaid on the smaller, demonstrating retraction from peripheral feeding grounds to the central core area

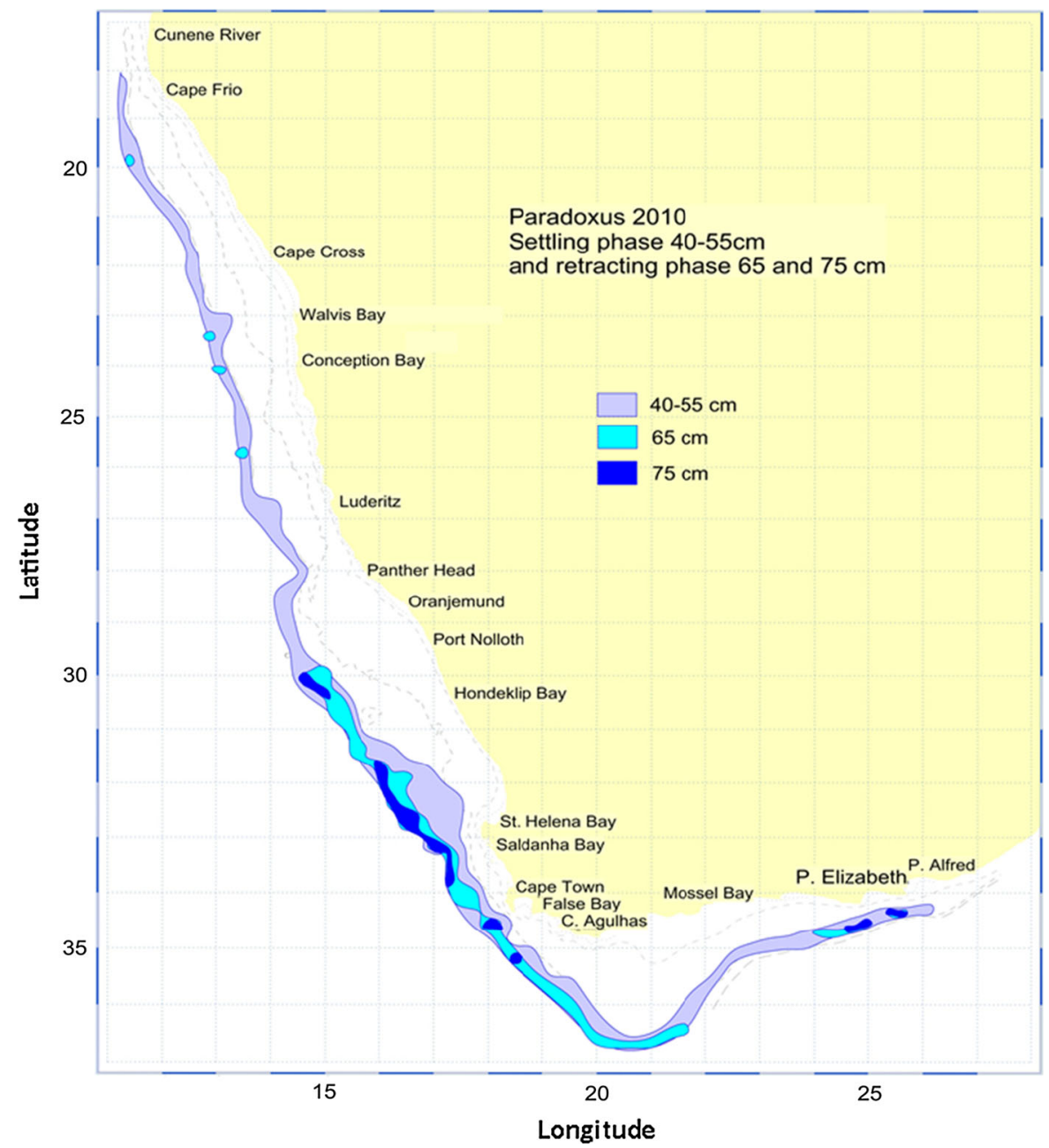

southern distribution and with a slight tendency to go shallower. The extreme years show that the general pattern holds but that there is a latitudinal shift for the size range beyond $25 \mathrm{~cm}$.

Comparison of stock dynamics between Namibia and South Africa

The data collected through the hake surveys provide estimates of biomass in weight and in numbers by length classes $(\mathrm{cm})$ for South Africa and Namibia separately and combined. An example of the distribution pattern of biomass for length group 20-24 cm is shown in Fig. 6. The biomass results are also compiled into diagrams showing the share of each length class by country. An example from 2012 is shown in Fig. 7, showing an increasing share of biomass in Namibia with increasing length in the range $15-35 \mathrm{~cm}$, from where it gradually recedes until $60 \mathrm{~cm}$ from where practically all fish is found in South Africa only. Figure 8 shows the inter-annual variability in biomass between the countries for eight annual surveys 2005-2012. The overall split between countries is seen to vary between years, but the general pattern of increased share in Namibia in the length range 15-35 is consistent as also is the sharp decline from the $55 \mathrm{~cm}$ group onwards. The arithmetic mean for all the surveys shows a plateau from 35 to $55 \mathrm{~cm}$ where the Namibian share varies but is close to 0.4 . The presence of young fish smaller than $15 \mathrm{~cm}$ shows a high variability between years with 2 years (2005 and 2006) showing a high presence of juveniles in Namibia, while in most years their presence is very low or they are absent. This dynamics are associated 


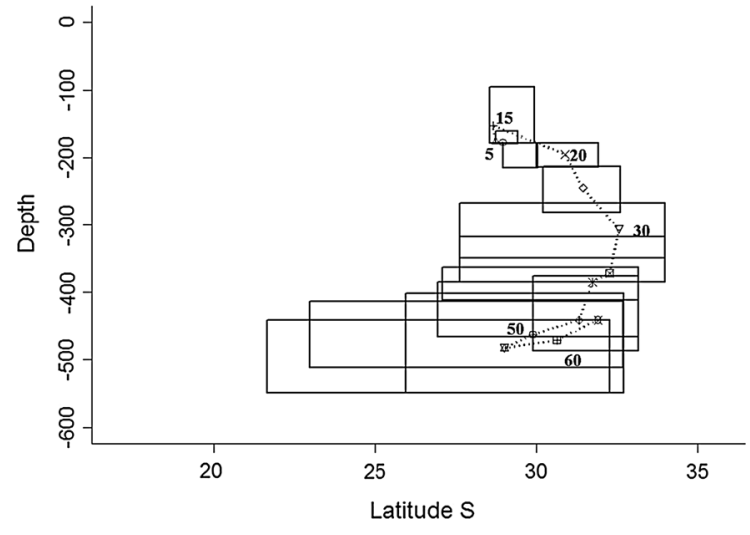

Fig. 4 Plots of the weighted centroid of 5-cm classes of deep water hake from 5 to $65 \mathrm{~cm}$, by latitude and depth. Boxes around the centroids delimit the 50-percentile of the biomass distribution in both dimensions. The dotted line between centroids, denote the "distribution signature" of the stock, referred to in the text. Number captions give the lower size range of the $5-\mathrm{cm}$ class (e.g. $20=20-24 \mathrm{~cm})$

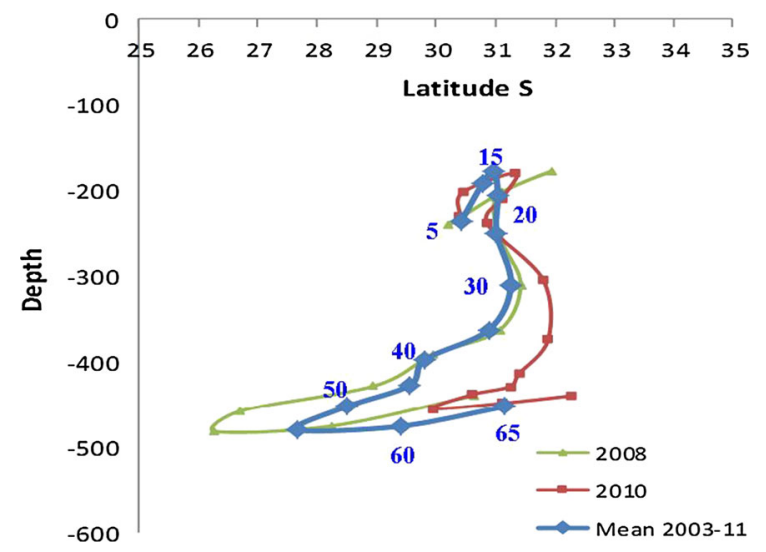

Fig. 5 Distribution of statistically weighted centroids for Merluccius paradoxus by latitude and depth for an average year (2003, 2005-2011) and for two extreme years 2008 and 2010. Number captions give the lower range of the 5-cm class

with the hydrographic conditions on the Orange Banks where under special circumstances a migration channel north into Namibia can be formed, as in 2005 and 2006 (Ostrowski et al. 2011).

These surveys also produce separate biomass estimates on the "fishable" part of the stock, i.e. all fish larger than $35 \mathrm{~cm}$. This can also be seen as the adult part of the stock that undertakes seasonal feeding and spawning migrations. This is also associated with the 'plateau' in Fig. 8. Figure 9a shows the fishable biomass in Namibia and South Africa plotted against

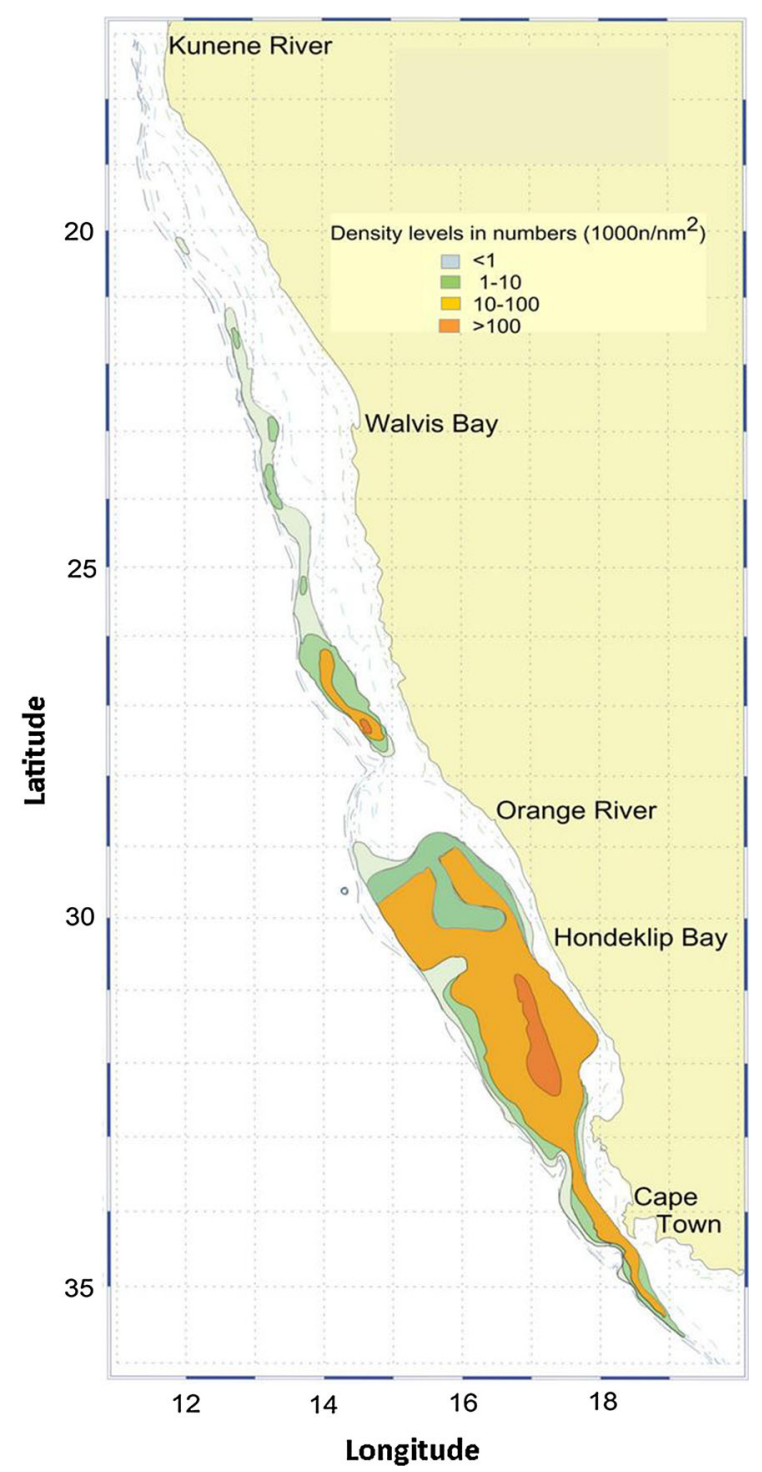

Fig. 6 Example of a distribution map of single length class (20-24 cm) of Merluccius paradoxus in the year 2009, by merging calibrated surveys in Namibia and South Africa

each other. Apart from the year 2010 a linear pattern emerges, where the biomass in the two countries shows high synchronicity. The extreme in 2010 coincides with southerly distribution shift as shown in Fig. 5.

A similar plot for the small fish less than $35 \mathrm{~cm}$ is given in Fig. 9b, and shows that most $(>75 \%)$ of the biomass is located in South Africa. There is no clear linearity between the two countries as observed for the adult hake. 


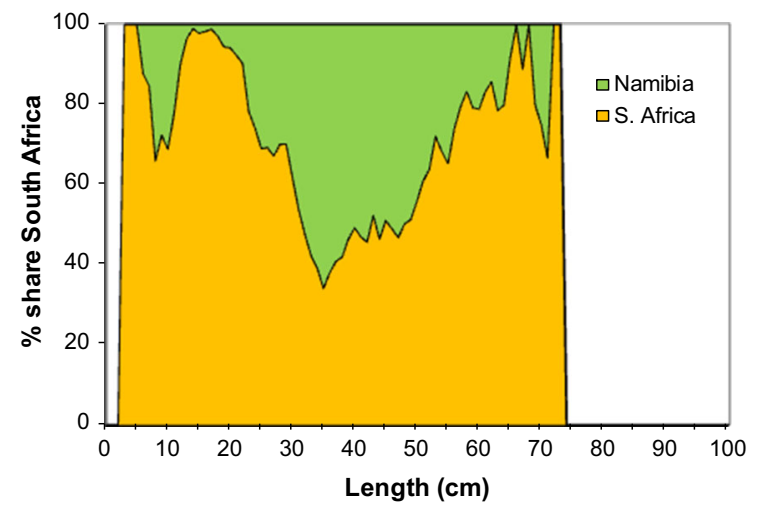

Fig. 7 Namibian and South African shares of biomass in numbers of Merluccius paradoxus individuals by 1-cm length classes in 2012

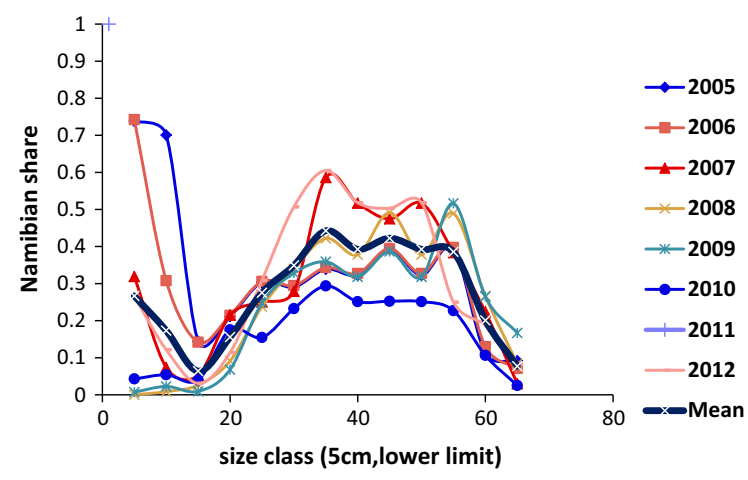

Fig. 8 Time series of Namibian share of Merluccius paradoxus biomass based on the surveys in the years 2005-2012, and arithmetic mean for all these years. The lowest and highest estimates are in 2010 and 2012, respectively

\section{Discussion}

Previous accounts of $M$. paradoxus biology and life cycle have stressed a relatively sedentary mode of life for this species. In particular, reasonably dispersed spawning and nursery areas throughout their distributional range as well as no (or limited) alongshore migrations were assumed. In stark contrast, our research provides documentation of a single welldefined spawning ground, a key well-defined nursery ground and alongshore movements of adult fish stretching hundreds of miles. These migrations, especially across national borders, may have profound implications for resource management of one of the most important fisheries in southern Africa.
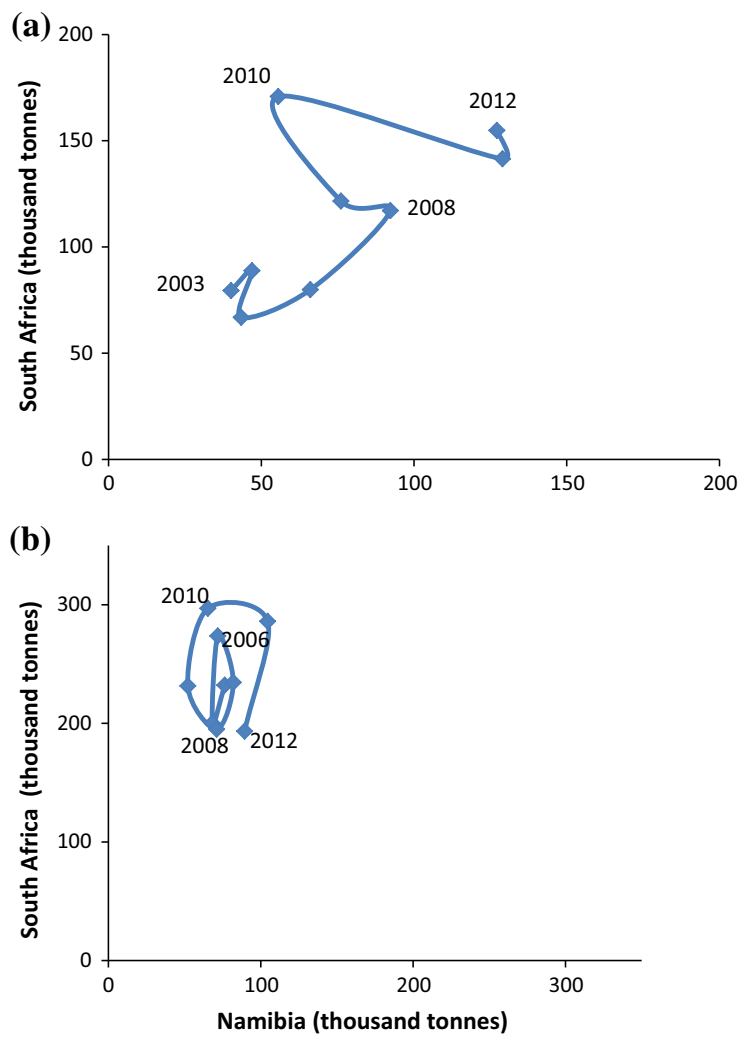

Fig. 9 a Trends in biomass relationship between adult component ( $>35 \mathrm{~cm}$ length) of Merluccius paradoxus stock in South Africa and in Namibia based on the surveys in 2003 and 2005-2012. b Trends in biomass relationship between young fish component of deep water hake in South Africa and in Namibia based on the surveys in 2003 and 2005-2012

Conceptual outline of pattern in geographic size distribution as a proxy for age classes of Merluccius paradoxus

\section{Spawning, larvae and juveniles}

Off Namibia, Kainge et al. (2007) found no evidence of spawning for M. paradoxus, based on a combination of histological examinations and of the gonadosomatic index (GSI). Spawning of DWH based on analysis of maturity stages is not adequately documented in the existing literature. There is substantial material available from South Africa and Namibia, based on the biological analyses completed on data from the demersal surveys and the commercial trawlers. This material needs to be critically reviewed and analyzed, although its significance may be somewhat limited by 
methodological debate about validity and meaning of morphological staging of the maturation process, as fish in the running stage are scarce (Kainge 2002; Kainge et al. 2007; Osborne 2004; Osborne and Mullins 2005). For example all Dr Fridtjof Nansen cruises since 2000 yielded a total of 20 individuals of $M$. paradoxus in the running stage from approximately 6500 adult fish examined (Lipinski and Alvheim, unpublished data). Previous research has been summarized by Burmeister (2005). Further analysis of all existing data, including material from Dr Fridtjof Nansen is also being undertaken (Jansen et al. 2015). However, taking into consideration methodological difficulties and a scarcity of running fish, possibly caused by inadequate sampling methods (Botha 1973; Payne and Punt 1995), determining exactly where and when $M$. paradoxus is spawning seems doubtful using morphological maturity indicators from the standard biomass surveys alone.

Specially designed egg and larvae surveys of $M$. paradoxus (subsequently identified genetically, Von der Heyden et al. 2007a), developed by modeling their possible transport and retention, are considered more useful and the first steps in this direction have been made (Stenevik et al. 2008; Grote et al. 2012b; Lett et al. 2006; Garavelli et al. 2012). Despite the spatial limitations of actual sampling (conducted, so far, only between Cape Agulhas and Doring Bay, Fig. 1), results of the modeling strongly suggest that the main spawning grounds for DWH are located between Agulhas Bank and St. Helena Bay (Garavelli et al. 2012) (Fig. 1). This suggestion is corroborated by evidence from all Dr Fridtjof Nansen demersal surveys concerning the distribution and abundance of early juveniles (see below). The Cape Egg and Larval Programme (CELP) records (Shelton 1986), indicating a year-round presence of hake larvae, is inconclusive as larvae were not identified to species nor their lengths measured and numbers per transect given. Circumstantial evidence provided by Assorov and Berenbeim (1983) that running fish were encountered "south of $22^{\circ} \mathrm{S}^{\prime \prime}$ cannot be considered as evidence because specific details were not presented. The authors drew their conclusions from 398 individuals collected over a period of 14 years.

Lack of evidence of early juveniles of $M$. paradoxus (in contrast to M. capensis) on the south coast of South Africa westward of Port Alfred (Le Clus et al. 2005a, b and pers. comm.; Fig. 2), seem to support Le
Clus et al. (2005a) conclusion that west coast spawning grounds supply south coast adults. In addition, it is likely that these originate from main pelagic nursery area between Hondeklip Bay and Orange Banks (since other nurseries are erratic and small), necessitating long-range migration southward and then eastward. There is anecdotal evidence of $M$. paradoxus spawning offshore between Mossel Bay and Port Elizabeth (Dave Japp, Capfish South Africa pers. comm.). This could perhaps explain the small enclave of large fish observed in the most eastern region (Fig. 3), but since juveniles are completely missing in this area, one possibility is that they may be located further east, outside the survey area. However, the oceanographic conditions there are not expected to be favorable for young hake. Observations of adult DWH in the waters of southern Mozambique confirms hake presence there, however at very low densities (Oddgeir Alvheim, pers.comm.).

\section{Nursery grounds}

Available data suggest that larvae of DWH drift northwards (Grote et al. 2007; Stenevik et al. 2008; Grote et al. 2012b; Lett et al. 2006; Garavelli et al. 2012). Their drift routes differ from that of $M$. capensis (Stenevik et al. 2008; Garavelli et al. 2012). Our data show consistent occurrence of small juveniles $(2-15 \mathrm{~cm})$ in great numbers in the area between Hondeklip Bay and Orange Banks which strongly indicates that this is the most important nursery for this species (Fig. 2 for year 2010, Fig. 5 for interannual variability). Most of the young fish are pelagic and settle to the bottom at about $20 \mathrm{~cm}$ length, and can be caught more representatively in the sampling trawl (Sætersdal et al. 1999). Other small and intermittent nurseries exist next to the main and only large spawning area of M. paradoxus, i.e. between Agulhas Bank and Elands Bay.

Further evidence of the main nursery location comes from matching the timing of appearance of juveniles with their back-calculated birth date. For this, data provided by Grote et al. (2012a) were used (Gompertz equation, Figs. 5 and 7 of Grote et al. 2012a). These results agree well with the quick growth hypothesis by de Pontual et al. (2006) and modeling of Drouineau et al. (2010), albeit for a different hake species. According to the results of Grote et al. (2012a), larvae and juveniles of the main length peaks 
of 100,170 and $240 \mathrm{~mm}$ are all over 150 days old. Current speed of $10 \mathrm{~cm} / \mathrm{s}$. resulted in a possible movement of over 550 nautical miles which can be easily covered in such time (M. Ostrowski, IMR Bergen, pers. comm.). However, only about 400 miles are necessary to cover the distance between Cape Point and Panther Head-Orange River. Even the youngest 60 day old juveniles will cover over 270 miles which would put their potential spawning place just north of Cape Columbine. Stable near bottom conditions over the relatively shallow (around $200 \mathrm{~m}$ ) mid-shelf of the Orange Banks are likely to provide favorable environment for the young stages of the DWH (Ostrowski et al. 2011).

\section{Recruits $(20-35 \mathrm{~cm})$; Adults $(>35 \mathrm{~cm})$}

From the central nursery area, $M$. paradoxus moves north (into Namibia) and south and then east to the south coast of South Africa. Migrations along the coast start at the size of approximately $20 \mathrm{~cm}$ and at the size of $35 \mathrm{~cm}$ up to $55 \mathrm{~cm}, 40 \%$ of the west coast hake is found in Namibia.

\section{Transboundary stock relationships between South Africa and Namibia}

Analysis of length frequencies over 9 years point to a migration of larger hake (over $35 \mathrm{~cm}$ ) to Namibia and over the size of $55 \mathrm{~cm}$ back to South Africa. The absence of large-size fish in Namibia could perhaps partly be explained by extensive fishing in the Luderitz area by Namibian trawlers. However the complete absence of DWH further north where fisheries are less intensive, points to a biological reason for this. Likewise, since there is no evidence of $M$. paradoxus spawning in Namibia (Burmeister 2005; Kainge et al. 2007) and since there are no small juveniles north of Orange Banks, one must assume that all fish of this species in Namibia have migrated northwards from the main nursery area off Hondeklip Bay-Orange Banks. Namibian M. paradoxus is thus an adult extension of the South African stock. This is further confirmed by the magnitude of Namibian catches of this species. Annual catch closely approaches the standing stock biomass estimate, and in some years (e.g. 2005) far exceeds it (Kirchner 2011) while the South African catch is only $37 \%$ of standing stock adult biomass
(Kirchner 2011). A regular and constant replenishment from south is the most plausible explanation for the sustained high exploitation rate in Namibian waters that otherwise would deplete the stock.

The presence of deep water hake adults in Namibia begs the question of where these fish spawn, i.e. do they return to the main spawning grounds from as far as the Skeleton Coast? Is this simply a part of the spawning biomass with annual spawning migrations or are they non-returning offshoots from a stock that is in an expanded state? The absence of very large fish in the region points to a southern return, at least when they reach $60 \mathrm{~cm}$, when they also seem to cease annual long range migration. There is no reason to suspect that natural or fishing mortality wipes out this group of old fish completely. A large-scale tagging program of the Namibian adult fish would certainly be helpful to better understand the intra-annual migration in the northern component, which is of high importance for developing a future management strategy.

Prior to Independence in 1990, the fish stocks off Namibia were heavily depleted through decades of international fishing outside the $12 \mathrm{NM}$ territorial waters, and the hake stocks in the newly declared EEZ were at their historical low (Sætersdal et al. 1999). The Dr Fridtjof Nansen surveyed the Namibian shelf with 16 trawl surveys in the period 1990-1999 thus initiating the Namibian time series of the demersal stock abundance. At the start in 1990 the presence of deep water hake in Namibia was remarkably low and present only in the southern part. The biomass index of the species was, for the first 2 years, only 25 thousand tonnes, increasing to 170 thousand tonnes over 3 years. DWH was gradually expanding northward and reached the coast off Kunene River in 1992 (Sætersdal et al. 1999). This constitutes additional evidence that the DWH in Namibia is part of the South African stock and possibly indicates that the stock during the time of the transboundary surveys was in an expanding phase.

\section{Spatial and temporal life cycle of M. paradoxus}

Data presented here confirm size-related depth distribution of DWH (Le Clus et al. 2005a) and extend the understanding of their geographic distribution. In particular, because of fine-scale analysis of size classes, a new understanding of fish distribution by 
sizes has been achieved. This study demonstrates that the smallest and largest $M$. paradoxus occur only in South Africa or around the border with Namibia (up to a northern tip of the Orange Banks, which is in Namibia): smallest in the main nursery area, and largest close to and north of the main spawning grounds, which corroborates the second working hypothesis (see section "Materials and methods"). Abundance proportions demonstrate that the west coast of South Africa provides the main habitat for this species: both spawning and nursery grounds are found there, and biomass/numbers in Namibia and along the south coast are of an order of magnitude smaller than on the west coast of South Africa. Spread of length classes along the west coast suggests long-range migration from the nursery area.

Le Clus et al. 2005a (and pers. comm.) have interpreted their data as supporting one main spawning ground and one nursery area for $M$. paradoxus in South Africa. They also report that juveniles of DWH are generally absent along the south coast. Those findings are consistent with those presented in this study. New evidence presented here suggests that most DWH on the south coast originate from the main nursery area between northern St. Helena Bay and Orange Banks. This implies a major migration of DWH which leaves this nursery on its way north (up to the Skeleton Coast in Namibia) and on its way south and then east (up to Port Alfred). There is however small local component of large fish offshore between Mossel Bay and Port Elizabeth.

There is evidence that although the relative distribution of various size classes along the coast may vary, patterns stay the same. The ratio of adult biomass between the countries is remarkably stable and increases and decreases are, with a few exceptions, synchronic. In contrast, the rather stable ratios of adult biomass may show sudden anomalies interpreted as a shift in biomass induced by changes in the normal migration between the two countries; 2010 was such an anomalous year. There was a considerable and sudden increase in the M. paradoxus biomass in South Africa corresponding to a sudden biomass decrease in Namibian waters (see also Kirchner 2011). In 2011-2012 the situation returned to normal. It is as yet unknown what triggered the geographic shift in biomass, but it was potentially due to environmental forcing. The anomaly also demonstrates the importance of continuous collection of transboundary time series data. A 1 year anomaly in biomass estimates due to geographical shifts could trigger alarms in national stock assessment models if information on the whole population/stock is not taken into account. On the other hand, a synoptic view of the stock would provide more accurate information on its actual state. Anomalies in the distribution could be part of the natural variability in the ecosystem, but could also be the result of more permanent changes of variability due to longer term changes in environmental parameters associated with climate change. It is therefore of high importance to further explore what mechanisms are triggering the geographical shifts in distribution.

\section{Management considerations}

The life cycle analysis presented in this paper clearly demonstrates that $M$. paradoxus is a transboundary species and should therefore be considered a shared resource between Namibia and South Africa. Spawning takes place in South Africa which is also the habitat for larvae and juveniles. Young fish move gradually to Namibia and to the South African south coast in extensive feeding migrations. This model supports the single stock hypothesis (Anon. 2006). This study results in a simple life cycle model, with a single main spawning area and a single main nursery area, and large-scale feeding and spawning migrations across the distribution range. The hypothesis of large-scale migrations was put forward early on (e.g. Roux 1949) and then refuted (Payne and Punt 1995) on the grounds that early works did not differentiate between the two species of hake. Hake migrations worldwide are not well investigated, but are reported in a few cases (e.g. Grinols and Tillman 1970; Nelson and Larkins 1970).

The present study demonstrates the shared nature of the DWH population off southwest Africa and provides some of the information needed for shared stock management. While it seems clear that Merluccius paradoxus does not spawn in Namibia; the extent to which large fish found in Namibia migrate back to South Africa for spawning is not confirmed. There are two possible scenarios: first, most of these fish return annually to spawning grounds in South Africa; or second, most of these fish are biologically lost for hake reproductive effort (i.e. do not return for spawning). The size related distribution maps strongly indicate that the large fish eventually return but the frequency and strength of the migration still needs to be 
demonstrated. This is one of the fundamental management-related questions for this species requiring increased research efforts, involving tagging and large-scale biological sampling for hake condition and maturity, especially in southern Namibia. Likewise, movement of adults of both hake species should be studied in detail, even inside national borders.

Recognizing the ecological differences between the two hake species, the implications of the current approach of combining the two into a single stock assessment model should also be further investigated. This may be a challenging task since fisheries catch records do not differentiate between the two species and the present split of the catch based on the depth in which hakes are caught are not completely satisfactory. This difficulty puts more emphasis on the importance of independent synoptic surveys.

Finally, it is highly recommended that the present management regime, based on the assumption of stocks confined within the respective national jurisdictions and combined in single assessments, is thoroughly evaluated.

Acknowledgments The authors wish to thank the technical staff that participated in the scientific surveys on board the R/V Dr F. Nansen and the F/V Blue Sea 1 for their hard work in collecting and organizing the data on which this study is based. In particular, Oddgeir Alvheim (IMR) is thanked for his invaluable support throughout all stages of preparation of this paper, especially with regards to the preparation of data and figures. The authors would also like to thank colleagues in Namibia and South Africa for sharing their knowledge and insights on various aspects of the biology of hake in the region. Malgosia Lipinska (University of Cape Town), two anonymous referees critically reviewed the manuscript. Finally the authors wish to thank the BENEFIT and the BCLME Programmes as well as the Benguela Current Commission for their support of this research work.

Open Access This article is distributed under the terms of the Creative Commons Attribution 4.0 International License (http:// creativecommons.org/licenses/by/4.0/), which permits unrestricted use, distribution, and reproduction in any medium, provided you give appropriate credit to the original author(s) and the source, provide a link to the Creative Commons license, and indicate if changes were made.

\section{References}

Anon (2006) Agreed report of the joint hake research planning workshop (Namibia and South Africa). BENEFIT/BCLME Cape Town 9-12 May 2006
Armstrong CW, Sumaila UR (2004) The Namibian-South African hake fishery: costs of non-cooperative management. In: Sumaila UR, Buyer D, Skogen MD, Steinshamn SI (eds) Namibia's fisheries: ecological, economic and social aspects. Eburon, Delft, The Netherlands, pp 231-243

Assorov VV, Berenbeim DY (1983) Spawning grounds and cycles of Cape hakes in the Southeast Atlantic. Colln scient Pap int Commn SE Atl Fish 10(1):27-30

Axelsen BE, Johnsen E (2015) An evaluation of the bottom trawl surveys in the Benguela Current Large Marine Ecosystem. Fish Oceanogr 24(Suppl. 1):74-87. doi:10. 1111/fog. 12079

Botha L (1973) Migrations and spawning behavior of the Cape hakes. S Afr Shipp News Fishg Ind Rev 28(4): 62-63, 65, 67

Botha L (1986) Reproduction, sex ratio and rate of natural mortality of Cape hakes Merluccius capensis Cast. and $M$. paradoxus Franca in the Cape of Good Hope area. S Afr J Mar Sci 4:23-35

Burmeister L (2005) Is there a single stock of Merluccius paradoxus in the Benguela ecosystem? Afr J mar Sci 27(1):23-32

de Pontual H, Groison AL, Pineiro C, Bertignac M (2006) Evidence of underestimation of European hake growth in the Bay of Biscay, and its relationship with bias in the agreed method of age estimation. ICES J Mar Sci 63:1674-1681

Drouineau H, Mahevas S, Bertignac M, Duplisea D (2010) A length-structured spatially explicit model for estimating hake growth and migration rates. ICES J Mar Sci 67(8):1697-1709

Field JG, Moloney CL, du Buisson L, Jarre A, Stroemme T, Lipinski MR, Kainge P (2008) Exploring the BOFFF hypothesis using a model of southern African deepwater hake (Merluccius paradoxus). In: Tsukamoto K, Kawamura T, Takeuchi T, Beard TD Jr, Kaiser MJ (eds) Fisheries for global welfare and environment, 5th World Fisheries Congress, Terrapub, pp 17-26

Garavelli L, Gruss A, Grote B, Chang N, Smith M, Verley P, Stenevik EK, Kaplan DM, Lett C (2012) Modeling the dispersal of Cape hake ichthyoplankton. J Plankt Res 34(8):655-669

Gordoa A, MacPherson E, Olivar MP (1995) Biology and fisheries of Namibian hakes ( $M$. paradoxus and $M$. capensis). In: Alheit J, Pitcher TJ (eds) Hake biology, fisheries and markets. Chapman \& Hall, London, pp 49-88

Grinols RB, Tillman MF (1970) Importance of the worldwide hake, Merluccius, resource. US fish and wildlife service. Circ 332:1-21

Grote B, Ekau W, Hagen W, Huggett JA, Verheye HM (2007) Early life-history strategy of Cape hake in the Benguela upwelling region. Fish Res 86:179-187

Grote B, Ekau W, Stenevik EK, Clemmesen K, Verheye HM, Lipinski MR, Hagen W (2012a) Characteristics of survivors - growth and condition of early life stages of the two hake species Merluccius paradoxus and $M$. capensis in the southern Benguela system. ICES J Mar Sci 69:553-562

Grote B, Stenevik EK, Ekau W, Verheye HM, Lipinski MR, Hagen W (2012b) Spawning strategies and transport of early stages of the two hake species, Merluccius paradoxus 
and $M$. capensis in the southern Benguela upwelling system. Afr J Mar Sci 34(2):195-204

Gunderson DR (1993) Surveys of fisheries resources. Wiley, New York, pp 15-16

Hilborn R, Walters CJ (1992) Quantitative fisheries stock assessment. Chapman \& Hall, London

Hutchings JA (2002) Life histories of fish. In: Hart PJB, Reynolds JD (eds) Handbook of fish biology and fisheries, vol 1. Blackwell Publishing, Oxford UK, pp 149-174

Jansen T, Kainge P, Singh L, Wilhelm M, Durholtz D, Strømme T, Kathena J, Erasmus V (2015) Spawning patterns of shallow-water hake (Merluccius capensis) and deep-water hake (M. paradoxus) in the Benguela Current Large Marine Ecosystem inferred from gonadosomatic indices. Fish Res 172:168-180. doi:10.1016/j.fishres.2015.07.009

Kainge PI (2002) Spawning time and reproductive investment of the hakes, Merluccius capensis and M. paradoxus, in the Namibian waters. Dissertation MPhil University of Bergen, Norway

Kainge P, Kjesbu OS, Thorsen A, Salvanes AG (2007) Merluccius capensis spawn in Namibian waters, but do $M$. paradoxus? Afr J Mar Sci 29(3):379-392

Kirchner C (2011) Status of deep-water hake. In: Japp DW, Purves MG, Wilkinson S, Kirchner C (eds) Benguela current large marine ecosystem, 2011 annual state of fish stocks report, the Secretariat of the Benguela Current Commission, Windhoek Namibia, pp 9-13

Le Clus F, Henning HF-KO, Osborne RF, Leslie RW (2005a) Size-dependent spatial dynamics of deep-water Cape hake Merluccius paradoxus density distribution on two coasts, 1990-2003. Marine and Coastal Management South Africa, Demersal Working Group document WG/01/05/ DH:4

Le Clus F, Henning HF-KO, Osborne RF, Leslie RW (2005b) Size-dependent spatial dynamics of shallow-water Cape hake Merluccius capensis density distribution on two coasts, 1990-2003. Marine and Coastal Management South Africa, Demersal Working Group Document WG/ 03/05/DH6

Lett C, Roy C, Levasseur A, van der Lingen CD, Mullon C (2006) Simulation and quantification of enrichment and retention processes in the southern Benguela upwelling ecosystem. Fish Oceanogr 15(5):363-372

Nelson MO, Larkins HA (1970) Distribution and biology of Pacific hake: a synopsis. US fish and wildlife service. Circ 332:23-33

Osborne RF (2004) Spawning biology of Merluccius capensis and M. paradoxus. Dissertation $\mathrm{PhD}$, University of the Western Cape

Osborne RF, Mullins PW (2005) Proposal to change Cape hake Merluccius capensis and M. paradoxus sexual maturity assessment employed during routine fish sampling onboard research and commercial vessels. Marine and Coastal Management South Africa, Demersal Working Group Document WG/10/05/DH36

Ostrowski M, Shillington F, Lipinski M (2011) The Orange Banks: topographic setting and mid-shelf hydrographic conditions at the northern extremity of the southern Benguela upwelling regime. ICES Annual Science Conference 19-23 September 2011 Gdansk Poland, Book of Abstracts: 47

Payne AIL, Punt AE (1995) Biology and fisheries of South African Cape hakes (M. capensis and M. paradoxus). In: Alheit J, Pitcher TJ (eds) Hake biology, fisheries and markets. Chapman \& Hall, London, pp 15-47

Roux ER (1949) Migrations of the Cape hake or stockfish (Merluccius capensis Cast.) on the west coast of South Africa. Trans R Soc S Afr 32(2):217-231

Sætersdal G, Bianchi G, Strømme T, Venema SC (1999) The Dr Fridtjof Nansen programme 1975-1993. Investigation of fishery resources in developing countries. History of the programme and review of results. FAO fisheries technical paper 391, Rome

Shelton PA (1986) Fish spawning strategies in the variable southern Benguela Current region. Dissertation $\mathrm{PhD}$, University of Cape Town

Stenevik EK, Verheye HM, Lipinski MR, Ostrowski M, Stromme T (2008) Drift routes of Cape hake eggs and larvae in the southern Benguela Current system. J Plankt Res 30:1147-1156

Strømme T, Iilende T (2001) Precision in systematic trawl surveys as assessed from replicate sampling by parallel trawling off Namibia. S Afr J Mar Sci 23:385-396

Von der Heyden S, Lipinski MR, Matthee CA (2007a) Mitochondrial DNA analyses of the Cape hakes reveal an expanding, panmictic population for Merluccius capensis and population structuring for mature fish in Merluccius paradoxus. Mol Phylogenet Evol 42:517-527

Von der Heyden S, Lipinski MR, Matthee CA (2007b) Speciesspecific genetic markers for identification of early lifehistory stages of Cape hakes, Merluccius capensis and Merluccius paradoxus in the southern Benguela current. J Fish Biol 70 (Suppl. B):262-268

Von der Heyden S, Lipinski MR, Matthee CA (2010) Remarkably low mtDNA control region diversity in an abundant demersal fish. Mol Phylogenet Evol 55:1183-1188

Wilhelm M (2012) Growth and otholith zone formation of Namibian hake Merluccius capensis. Dissertation PhD, Department of Zoology University of Cape Town 